\title{
Statistical modeling of residential complex construction project
}

\author{
Pavel Morozovskiy ${ }^{1, *}$, Ilya Kulish ${ }^{1}$ and Denis Muradov ${ }^{1}$, and Kirill Kulakov ${ }^{2}$ \\ ${ }^{1}$ Peter the Great St. Petersburg Polytechnic University, 195251 St. Petersburg, Russia \\ ${ }^{2}$ Moscow State University of Civil Engineering, 26, Yaroslavskoye shosse, Moscow, 129337, Russia
}

\begin{abstract}
The article presents a statistical simulation of the deviation of the project duration from the planned value. Regression analysis was carried out - a method of statistical data processing that allows measuring the relationship between one or more causes (factor characteristics) and the consequence (effective characteristic). The end result is a curve and a correlation coefficient, which with a certain probability will allow us to predict the amount of pecuniary injury in this project.
\end{abstract}

\section{Introduction}

In the practice of modeling systems, one often has to deal with objects that contain elements of stochasticity or exposed to stochastic effects of the environment, which, in turn, affect the duration of construction. Therefore, the main method of obtaining results using simulation models of such stochastic systems is the method of statistical modeling on a computer $[1,2]$.

\section{MS Project statistical modeling}

In the Microsoft Project software package, statistical modeling of the deviation of the project duration from the planned value was performed. The first step was a regression analysis - a method of statistical data processing that allows you to measure the relationship between one or more causes (factor features) and the consequence (effective feature). The work of the generator was carried out under the condition that the baseline cost is less than zero, the percentage of delay- $5 \%$ of the base duration.

Unexpected deviations given the statistical variation in the duration of 1274.87 to 1321.04 days taking into account the period of return (Fig. 2). On the basis of the basic plan, the method of determining the probabilistic values of the duration, taking into account the acceleration or delays in the project, depending on unforeseen factors, 50 variants of the duration of work were obtained, the pecuniary injury for each of these options was determined [9-14].

\footnotetext{
*Corresponding author: morozovoff85@gmail.com
} 


\begin{tabular}{|c|c|c|c|c|c|c|c|c|c|}
\hline & Name & $\begin{array}{l}\text { Statistic } \\
\text { duration(1- }\end{array}$ & Cash flow(rubles) & $\begin{array}{l}\text { Baseline } \\
\text { cost(rubles) }\end{array}$ & $\begin{array}{l}\text { Scheduled } \\
\text { duration(d. }\end{array}$ & Generatori. & Scheduled NPV . & Statistic NPV - & $\begin{array}{l}\text { Pecuniary } \\
\text { injury(rubles) }\end{array}$ \\
\hline 0 & $\triangle$ Res. complex & 1299.84 & 402303306.00 & 402303306.00 & 1269 & 0 & 459342448.71 & 455266118.3 & 4076330.41 \\
\hline 1 & Parking 1 & 300.82 & -121872289.00 & -121872289.00 & 289 & 299.33 & -133606377.64 & -134068505.57 & 462127.93 \\
\hline 2 & G corp & 461.72 & -217983276.00 & -217983276.00 & 460 & 473.56 & -249843253.05 & -250811270.09 & 968017.05 \\
\hline 3 & Parking 2 & 231.58 & -117555679.00 & -117555679.00 & 230 & 240.07 & -126544333.1 & -126594317.6 & 49984.5 \\
\hline 4 & H corp & 422.45 & -226796616.00 & -226796616.00 & 418 & 429.85 & -257421034.09 & -257981286.46 & 560252.37 \\
\hline 5 & Parking 3 & 210.76 & -54964834.00 & -54964834.00 & 204 & 205.96 & -58236228.18 & -58592727.65 & 356499.47 \\
\hline 6 & K corp & 326.54 & -163897200.00 & -163897200.00 & 316 & 322.32 & -179390929.99 & -181070379.08 & 1679449.09 \\
\hline 7 & $\triangle$ Earnings & 0 & 1305373200.00 & 1305373200.00 & 365 & 0 & 1464384604.75 & 1464384604.75 & 0 \\
\hline 8 & Parking 1 & 365 & 9744000.00 & 9744000.00 & 365 & 365 & 10930945.72 & 10930945.72 & 0 \\
\hline 9 & G corp & 365 & 494423600.00 & 494423600.00 & 365 & 365 & 554650814.09 & 554650814.09 & 0 \\
\hline 10 & Parking 2 & 365 & 9312000.00 & 9312000.00 & 365 & 365 & 10446322.51 & 10446322.51 & 0 \\
\hline 11 & $H$ corp & 365 & 479584600.00 & 479584600.00 & 365 & 365 & 538004231.22 & 538004231.22 & 0 \\
\hline 12 & Parking 3 & 365 & 4320000.00 & 4320000.00 & 365 & 365 & 4846232.09 & 4846232.09 & 0 \\
\hline 13 & K corp & 365 & 307989000.00 & 307989000.00 & 365 & 365 & 345506059.13 & 345506059.13 & 이 \\
\hline
\end{tabular}

Fig. 1. MS Project calculation of pecuniary injury.

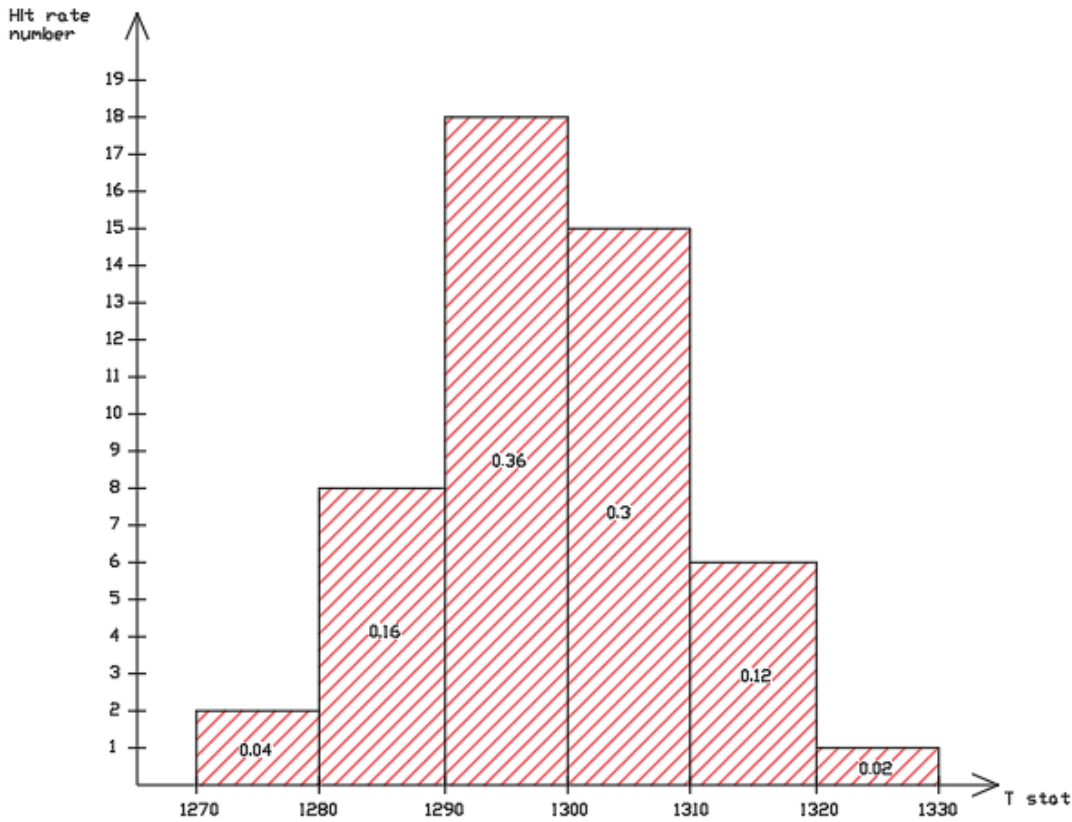

Fig. 2. Distribution of the static duration of monetary damage by intervals.

On the basis of the basic plan, the method of determining the probabilistic values of the duration, taking into account the acceleration or delays in the project, depending on unforeseen factors, 50 variants of the duration of work were obtained, the pecuniary injury for each of these options was determined. The monetary damages were divided into 6 intervals with a step of 1000000 , the values of static duration-into 6 intervals with a step of 10 days (Fig. 3) [8]. 


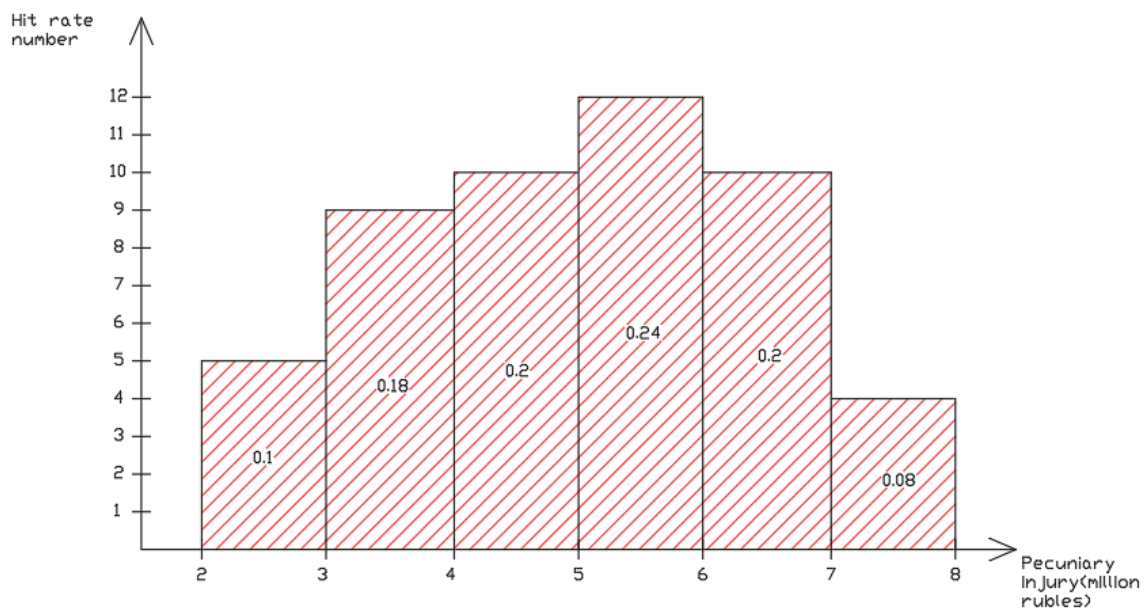

Fig. 3. Distribution of the static duration of pecuniary injury by intervals.

\section{MS Office Excel statistical modeling}

Performed statistical modeling consists in the construction and evaluation of the adequacy of the probabilistic model of the process of capital construction. For $\mathrm{x}_{\mathrm{i}}$ adopted statistical duration of construction (days). The number of $\mathrm{K}_{\mathrm{i}}$ measurements in which $\mathrm{x}_{\mathrm{i}}$ values are observed and the relative frequencies of $\mathrm{n}_{\mathrm{i}}$ are determined.

The following values are obtained:

Mathematical expectation $\mathrm{M}(\mathrm{x})=1298.6$ days.

Dispersion of a random variable $\mathrm{D}(\mathrm{x})=115.04$ days.

Standard deviation $\sigma=\mp 10.73$, showing the dispersion of the values of a random variable (duration) relative to its mathematical expectation.

The correlation analysis is carried out and the regression equation is made. The purpose of correlation analysis is to identify estimates of the strength of the relationship between random variables - duration and loss, which characterizes the construction process. For $\mathrm{X}$ accept statistical duration (days), Y - loss (rubles).

\begin{tabular}{|c|c|c|c|c|c|c|c|}
\hline$x_{i} ; x_{i}+1$ & $1270-1280$ & $1280-1290$ & $1290-1300$ & $1300-1310$ & $1310-1320$ & $1320-1330$ & Sum \\
\hline$k_{i}$ & 2 & 8 & 18 & 15 & 6 & 1 & 50 \\
\hline$n_{i}$ & 0.04 & 0.16 & 0.36 & 0.3 & 0.12 & 0.02 & 1 \\
\hline$x_{i} k_{i}$ & 2550 & 10280 & 23310 & 19575 & 7890 & 1325 & 64930 \\
\hline$x_{i} k_{i} / n$ & 51 & 205.6 & 466.2 & 391.5 & 157.8 & 26.5 & 1298.6 \\
\hline
\end{tabular}

\begin{tabular}{|c|c|c|c|c|c|c|c|}
\hline$M x=1298.60$ & & $D x=115.04$ & & $G=10.73$ & & & \\
\hline$x_{i} ; x_{i}+1$ & $2-3$ & $3-4$ & $4-5$ & $5-6$ & $6-7$ & $7-8$ & sum \\
\hline$k_{i}$ & 5 & 9 & 10 & 12 & 10 & 4 & 50 \\
\hline$n_{i}$ & 0.1 & 0.18 & 0.2 & 0.24 & 0.2 & 0.08 & 1 \\
\hline$x_{i} k_{i}$ & 12500000 & 31500000 & 45000000 & 66000000 & 65000000 & 30000000 & 250000000 \\
\hline$x_{i} k_{i} / n$ & 250000 & 630000 & 900000 & 1320000 & 1300000 & 600000 & 5000000 \\
\hline
\end{tabular}

Mx $=5$ millions

$\mathrm{Dx}=2.09 \mathrm{E}+12$

$G=1445683$

Fig. 4. MS Office Excel calculations of statistical values of durations and pecuniary injury. 
The following values are defined:

- Sample averages:

$$
\bar{x}=1298.27 ; \bar{y}=5043674.01
$$

- Sampling dispersion averages:

$$
S_{x}^{2}=104.26 ; S_{y}^{2}=2205917940724
$$

- Standard deviation

$$
S_{x}=10.21 ; S_{y}=1485233.3 ; S_{x y}=13061688
$$

As a result, the correlation coefficient $r_{x y}=0.86$ is obtained. This value shows that the relationship between the statistical length and loss is high (on a scale of Chedoke value falls within the interval of $\left.0.7<\mathrm{r}_{\mathrm{xy}}<0,9\right)$.

The regression equation:

$$
y=125285 x-157610149
$$

The coefficient $\mathrm{a}=243114.34$ shows the average change in the effective indicator (in rubles) with an increase or decrease in the value of the factor $\mathrm{x}$ (duration) per unit of its measurement. It turns out that with an increase of 1 unit y increases by an average of 125285 .

The coefficient $\mathrm{b}=-157610149$ formally shows the predicted level $\mathrm{y}$, but only if $\mathrm{x}=0$ is close to the sample values.

The relationship between $y$ and $x$ determines the sign of the regression coefficient $b$. If $b$ $>0$ is a direct link, $\mathrm{b}<0$ is an inversely proportional. In this project link is inversely proportional.

\section{Results and Discussion}

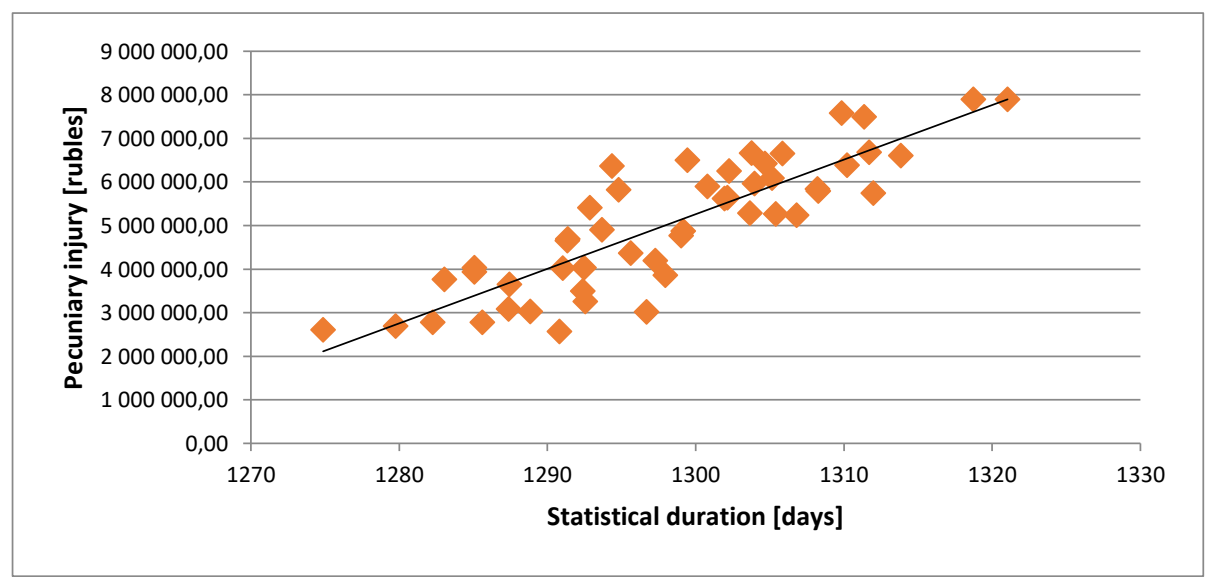

Fig. 5. Value distribution graph.

\section{Conclusions}

The conducted correlation analysis and the obtained correlation value allow us to conclude that the degree of tightness between days and pecuniary injury is high, which indicates the reliability of the project of capital construction of the residential complex. 
Thus, with high probability it is possible to predict the amount of pecuniary injury from late completion. All data of duration and pecuniary injury have a Gaussian distribution (Fig. $2,3)$.

\section{References}

1. N.V. Braila, Y.G. Lazarev, M. Romanovich, T.L. Simankina, A.V Ulybin, Contemporary problems in building science, engineering and technology (SPbPU, $\mathrm{SPb}, 2017)$

2. Calculated indicators to determine the duration of construction. Volume 1. The estimated indicators (graphs) to determine the duration of the construction of enterprises, buildings and structures (TSITP of the APT, Moscow, 1991)

3. Russian Federation Standard SNiP IV-2-84 part IV

4. Russian Federation Standard SNiP 1.04.03-85*

5. V.D. Ardzinov, Pricing and budgeting in construction (Piter, SPb, 2006)

6. I.G. Osipenkova, T.L. Simankina, R.R. Nurgalina, Basics of organization and management in construction (textbook) (St. Petersburg. state arch.-builds. Univ., SPb, 2014) ISBN 978-5-9227-0474-8

7. T.L. Simankina, Improvement of scheduling of resource-saving flows taking into account additivity of labor intensity of performers, dissertation (SBpPU, St. Petersburg, 2007)

8. I.S. Ptukhina, Simulation of calendar planning in building information modeling programs and regression specification of construction duration norms (SBpPU, St. Petersburg, 2011) 